\title{
Preliminary Safety Assessment for an IFE Target Fabrication Facility
}

J.F. Latkowski, S.Reyes, G.E. Besenbruch, and D.T Goodin

This article was submitted to

$14^{\text {th }}$ Topical Meeting on the Technology of Fusion Energy, Park City, UT, October 15-19, 2000

\section{October 13, 2000}

U.S. Department of Energy

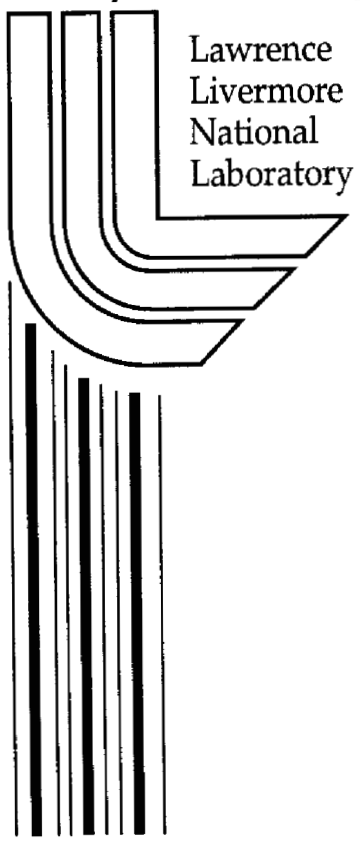




\section{DISCLAIMER}

This document was prepared as an account of work sponsored by an agency of the United States Government. Neither the United States Government nor the University of California nor any of their employees, makes any warranty, express or implied, or assumes any legal liability or responsibility for the accuracy, completeness, or usefulness of any information, apparatus, product, or process disclosed, or represents that its use would not infringe privately owned rights. Reference herein to any specific commercial product, process, or service by trade name, trademark, manufacturer, or otherwise, does not necessarily constitute or imply its endorsement, recommendation, or favoring by the United States Government or the University of California. The views and opinions of authors expressed herein do not necessarily state or reflect those of the United States Government or the University of California, and shall not be used for advertising or product endorsement purposes.

This is a preprint of a paper intended for publication in a journal or proceedings. Since changes may be made before publication, this preprint is made available with the understanding that it will not be cited or reproduced without the permission of the author.

This report has been reproduced directly from the best available copy.

Available to DOE and DOE contractors from the Office of Scientific and Technical Information P.O. Box 62, Oak Ridge, TN 37831

Prices available from (423) 576-8401 http://apollo.osti.gov/bridge/

Available to the public from the National Technical Information Service U.S. Department of Commerce 5285 Port Royal Rd., Springfield, VA 22161 http://www.ntis.gov/

\section{OR}

Lawrence Livermore National Laboratory Technical Information Department's Digital Library http://www.llnl.gov/tid/Library.html 


\title{
PRELIMINARY SAFETY ASSESSMENT FOR AN IFE TARGET FABRICATION FACILITY
}

\author{
J. F. Latkowski ${ }^{a}$, S. Reyes ${ }^{a}$, G. E. Besenbruch ${ }^{b}$, and D. T. Goodin ${ }^{b}$ \\ ${ }^{a}$ Lawrence Livermore National Laboratory, P. O. Box 808, L-446, Livermore, CA 94550 \\ ${ }^{b}$ General Atomics, P. O. Box 85608, San Diego, CA 92186
}

\begin{abstract}
We estimate possible ranges of tritium inventories for an inertial fusion energy (IFE) target fabrication facility producing various types of targets and using various production technologies. Target fill is the key subtask in determining the overall tritium inventory for the plant. By segmenting the inventory into multiple, parallel production lines-each with its own fill canister-and including an expansion tank to limit releases, we are able to ensure that a target fabrication facility would meet the accident dose goals of $10 \mathrm{mSv}$ (1 rem) set forth in the Department of Energy's Fusion Safety Standards. For indirect-drive targets, we calculate release fractions for elements from lithium to bismuth and show that nearly all elements meet the dose goal. Our work suggests directions for future R\&D that will help reduce total tritium inventories and increase the flexibility of target fabrication facilities.
\end{abstract}

\section{INTRODUCTION}

Designing fusion power plants for safe operation and limited, acceptable accident consequences will be essential for fusion to be successful. Typical IFE power plant designs call for repetition rates of $5-10 \mathrm{~Hz}(\sim$ 500,000 targets per day). Most target designs require $0.8 \mathrm{TBq}(\sim 20 \mathrm{Ci})$ of tritium, so the daily throughput will be on the order of $1 \mathrm{~kg}$. However, the steady-state tritium inventory, and thus, the quantity of tritium that might be mobilized during a severe accident is a function of the target fabrication and fill technologies. For indirect-drive target designs, radioactive, recycled target materials will also be present in the target fabrication facility.

In the present work, we estimate the steady-state tritium inventory for various target fill technologies. Aerosol transport calculations are used to model tritium and high- $\mathrm{Z}$ material releases, and the resulting doses are compared to a site boundary dose of $10 \mathrm{mSv}$ (1 rem) in each case-the limit specified in the Fusion Safety Standards (FSS). ${ }^{1}$

\section{TARGET DESIGNS}

The total tritium inventory is a strong function of the specific target design. A brief summary of the features of each target is included.

\section{A. Indirect-Drive Targets}

The indirect-drive targets considered are the heavyion-driver, distributed radiator designs. ${ }^{2,3}$ The "full-size" target is driven by $5.9 \mathrm{MJ}$ for a gain of 68 , while the "close-coupled" target requires only 3.3 MJ and has a gain of 133. The tritium inventories of the capsules are both $\sim 2.4 \mathrm{mg}$, but the target volumes are $1.6 \mathrm{cc}$ for the full-size target and $0.7 \mathrm{cc}$ for the close-coupled design. Although both designs use a beryllium shell and ablator, IFE power plant designs will probably use plastic shells to enable diffusion fill of targets.

Indirect-drive targets require high- $Z$ materials for the generation of $x$-rays. By using mixtures of materials, designers fill holes in the opacity and improve the target performance. Although baseline target designs call for a high- $Z$ cocktail of gold and gadolinium, neither material is particularly attractive from cost, fabrication, or extraction perspectives. Fortunately, recent work has shown that other materials are able to provide similar performance. ${ }^{4}$ Given this, we chose to consider the safety implications of using any of the natural chemical elements from lithium to bismuth. While previous work considered the contact dose rate, waste disposal rating, and accident dose resulting from all 264 stable isotopes, the accident doses were artificially high due to the use of very conservative radionuclide release fractions. ${ }^{5}$ In the present work, we calculate a single release fraction assuming that the initiating accident creates a fine particulate and that this particulate is transported out of the fill canister along with the tritium.

\section{B. Direct-Drive Targets}

For direct-drive targets, we also assume a range of designs. At one extreme, we assume the plastic shell ablator with a solid DT fuel layer from the Sombrero power plant study. ${ }^{6}$ This target would contain $2.4 \mathrm{mg}$ of tritium, yield $400 \mathrm{MJ}$, and be shot at $\sim 6.7 \mathrm{~Hz}$ for a 1000 $\mathrm{MW}_{\mathrm{e}}$ power plant. At the other extreme, Bodner et al. have published a target that uses a $\mathrm{CH}$ foam ablator filled with frozen DT. ${ }^{7}$ This target has a slightly higher tritium inventory of $2.5 \mathrm{mg}$. More importantly, calculations have only progressed to the point of showing a gain of 125 from 1.3 MJ of $\mathrm{KrF}$ laser energy for a yield of $163 \mathrm{MJ}$. With such a low burn-up (11\%), a $1000 \mathrm{MW}_{\mathrm{e}}$ power 
plant would require a tritium throughput close to $3.5 \mathrm{~kg}$ of tritium per day and a repetition rate of $\sim 14 \mathrm{~Hz}$. Our tritium inventory estimates correct for this special case by increasing the target production to 1.2 million per day. It is, of course, far from certain that a plant could be operated at such a high repetition rate. Ongoing work is concentrating on a design variation with $\sim 400 \mathrm{MJ}$ yield that would allow operation at $5-6 \mathrm{~Hz}^{8}$

\section{TRITIUM INVENTORY ESTIMATION}

For the purpose of estimating tritium inventories, we assume a daily throughput of 500,000 targets each of which yield $400 \mathrm{MJ}$. The exception to this case is for the direct-drive $\mathrm{CH}$-foam target, where we assume a daily throughput of 1.2 million targets. In determining the tritium inventory for the target fabrication facility, we assume that the facility is divided into multiple, parallel production lines. Each production line is capable of manufacturing a 3-hour supply of targets in each batch (62,500 targets/batch for all but the CH-foam target, which includes 150,000 targets/batch). In all cases, the target fill time is a key parameter in determining the overall inventory. For the indirect-drive cases, the relative timing of target fill and assembly is also of importance.

Figure 1 is a schematic of two parallel production lines being fed by the tritium reservoir. Each line includes target fill, cool down, and pump out. At the end of each line, filled targets go to layering, while the pumped-out DT gas goes either to the tritium clean-up system or back to the reservoir. Following layering, targets are injected, and unburned and bred tritium is recovered from the chamber and coolant. In reality, there may be many more production lines, and they will be staggered to ensure the staggered completion of targets.

\section{A. Target Fill Time}

For all of the target designs considered, filling the target with DT gas at high-pressure is the pacing step in the production process. For indirect-drive targets, times range from 24 hours if filled at a temperature of $300 \mathrm{~K}$ down to 11 hours for a temperature of $400 \mathrm{~K}$. The peak pressures are 68 and $84 \mathrm{MPa}$, respectively. The remaining steps are expected to require $\sim 6$ hours.

For direct-drive targets, capsule fill times are significantly longer due to the relatively thin-walled capsules, which will not support as great a pressure gradient. For a fill temperature of $300 \mathrm{~K}, 580$ hours would be required with a peak pressure of $128 \mathrm{MPa}$. At $400 \mathrm{~K}$ and a peak pressure of $161 \mathrm{MPa}$, the fill time is still 285 hours. Clearly, research and development into materials with higher diffusion rates or the ability to handle higher temperatures is needed. A program to study the effects of injection filling of targets with liquid DT could also be of benefit.

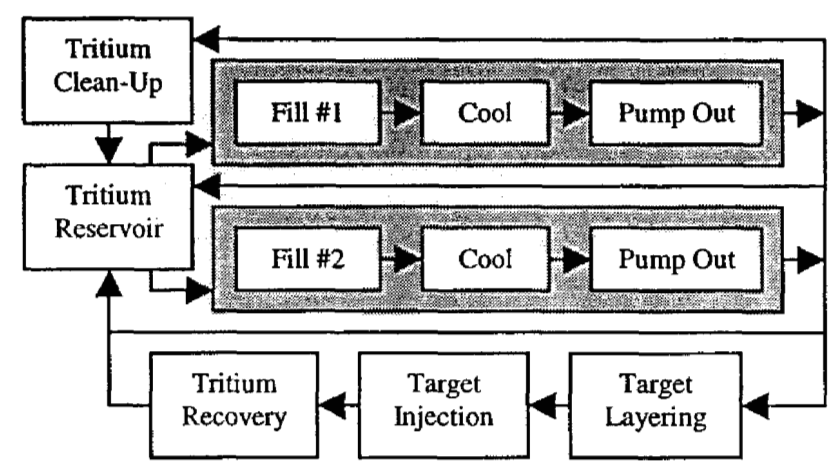

Fig. 1. Target fabrication occurs in multiple, parallel production lines.

\section{B. Hohlraum Assembly}

Another key issue for indirect-drive targets is the ordering of target fill relative to target assembly. If capsules can be filled, cooled, and then assembled into hohlraums-"cold assembly"-then only the capsule volume must be accommodated in the fill canisters. The simplest approach, however, is warm assembly followed by diffusion fill of the capsule while it resides within a hohlraum (a small hole would allow DT gas to enter the interior of the hohlraum). With warm assembly, one must accommodate the entire hohlraum volume, and thus, peak tritium inventories within a canister are significantly higher. For the full-size target, warm assembly leads to canisters that are $30 \times$ larger, while the close-coupled target requires $13 \times$ as much volume.

\section{Tritium Inventories}

Tritium inventories have been estimated for a range of cases. Table I summarizes results in the best and worst case for each class of targets. The best results assume the minimum fill time (and cold assembly for the indirectdrive cases), while the worst results assume the maximum fill time (and warm assembly followed by fill within the hohlraum for the indirect-drive cases). For indirect-drive targets, the plant tritium inventory ranges from 0.8 to $11.3 \mathrm{~kg}$ for the close-coupled target and 0.8 to $25.7 \mathrm{~kg}$ for the full-size target. For the direct-drive, plastic targets, the tritium inventory varies from 12.7 to $25.7 \mathrm{~kg}$ and depends entirely upon the fill temperature, which determines the fill time. The $\mathrm{CH}$-foam targets have a lower burn fraction, and thus, the tritium throughput and plant inventory would be higher for a $1000 \mathrm{MW}_{\mathrm{c}}$ power plant. The tritium inventory would range from 32.2 to $65.1 \mathrm{~kg}$. Again, the range is determined entirely by the diffusion fill time. Clearly, these results show the tremendous benefits of fast diffusion fill times and the ability to perform cold 
assembly. It is worth noting that none of the tritium inventory estimates includes a quantity going through the tritium clean-up system or an allowance for additional targets in storage in case of a system failure.

Table I. Basic tritium parameters for a target fabrication facility.

\begin{tabular}{|l|c|c|c|c|c|}
\hline \multicolumn{1}{|c|}{ Case } & $\begin{array}{c}\text { Capsule fill } \\
\text { time (h) }\end{array}$ & $\begin{array}{c}\text { Canister } \\
\text { volume (L) }\end{array}$ & $\begin{array}{c}\text { Peak canister T } \\
\text { inventory (kg) }\end{array}$ & $\begin{array}{c}\text { \# of } \\
\text { canisters }\end{array}$ & $\begin{array}{c}\text { Total plant T } \\
\text { inventory (kg) }\end{array}$ \\
\hline $\begin{array}{l}\text { Indirect-drive: Full-size or close-coupled target/400 K fill/Cold } \\
\text { assembled }\end{array}$ & 11 & 5.9 & 0.26 & 6 & 0.8 \\
\hline Indirect-drive: Full-size target/300 K fill/Warm assembled & 24 & 116 & 5.15 & 10 & 25.7 \\
\hline Indirect-drive: Close-coupled target/300 K fill/Warm assembled & 24 & 51 & 2.25 & 10 & 11.3 \\
\hline Direct-drive: Plastic target/400 K fill & 285 & 5.9 & 0.26 & 97 & 12.7 \\
\hline Direct drive: Plastic target/300 K fill & 580 & 5.9 & 0.26 & 196 & 25.7 \\
\hline Direct-drive: CH-foam target/400 K fill & 285 & 14 & 0.66 & 97 & 32.2 \\
\hline Direct drive: CH-foam target/300 K fill & 580 & 14 & 0.66 & 196 & 65.1 \\
\hline
\end{tabular}

\section{RADIONUCLIDE RELEASE MODELING}

Tritium and high- $Z$ releases have been modeled using a version of the MELCOR code that has been modified for use in fusion applications. ${ }^{8}$ Tritium is transported in the more radiotoxic HTO form. Lead particulate is transported as an example high- $\mathrm{Z}$ material. The MELCOR model consists of multiple volumes. A schematic of the release model is shown in Figure 2. With the exception of the canister, all volumes are initially at a slight underpressure of $\sim 500 \mathrm{~Pa}(2$ " water equivalent). This underpressure has little effect during an accident but it will help keep routine releases to low levels.

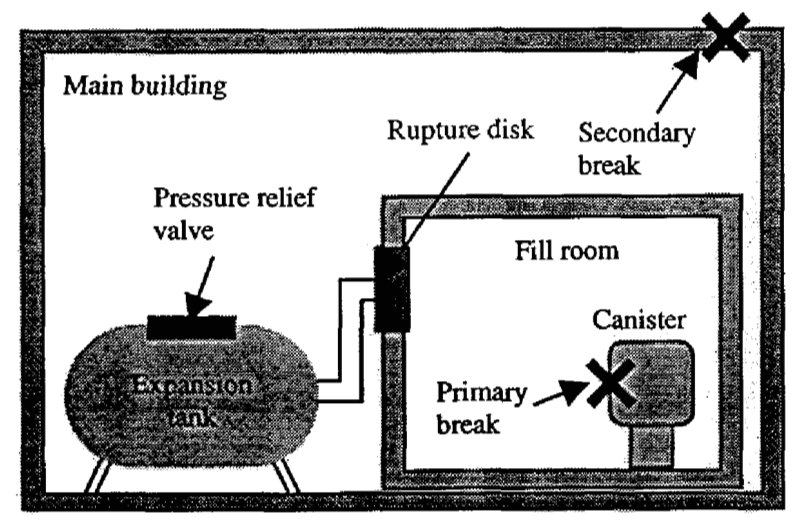

Fig. 2. The MELCOR release model includes isolated fill rooms and an expansion tank to limit the accident dose.

The accident analysis begins with an initiating event in a single canister - we assume a break with an area of 1 $\mathrm{cm}^{2}$. The high-pressure DT gas rapidly leaks from the canister into the fill room. In this simple analysis, each fill room has a volume of $12 \mathrm{~m}^{3}$, but this would have to be reduced for the direct-drive cases, which have a large number of canisters. Each fill room is equipped with a rupture disk that fails at an overpressure of $10 \mathrm{kPa}$. The disk area is $10 \mathrm{~cm}^{2}$, and each fill room is connected to an expansion tank by a pipe. We assume that the fill rooms serve to isolate the canisters; a failure of one canister will not affect the other canisters.
Once the rupture disk fails, tritium and high- $Z$ particulate flow into the expansion tank. The expansion tank is equipped with a pressure relief valve (PRV) that opens at an overpressure of $10 \mathrm{kPa}$. While a rupture disk never closes once it fails, PRVs are able to return to a closed state once the pressure differential falls below 10 $\mathrm{kPa}$. Gas released from the expansion tank flows into the larger confinement building and may be released to the environment via a $1 \mathrm{~m}^{2}$ break in the building. We take no credit for filtration, and we conservatively assume a ground-level release. Early doses are calculated assuming typical weather conditions.

For the high- $Z$ particulate, we assume a conservative particle size distribution (PSD) of 0.1-10 $\mu \mathrm{m}$ diameter. Such small particles are apt to transport great distances before settling. This PSD is conservative, because there is no clear mechanism for production of such fine particles.

\section{A. Tritium Results}

The tritium release fractions depend strongly upon the size of the expansion tank. In all cases, we have assumed an expansion tank that is a 5-m-long cylinder with hemispherical ends. As the radius increases from 2 to $3.5 \mathrm{~m}$, the tank volume increases from 96 to $372 \mathrm{~m}^{3}$. As would be expected, the release fractions are the greatest for the smallest expansion tank with the largest canister volume at the highest temperature and pressure (full-size target design with warm assembly and fill at $400 \mathrm{~K} / 84 \mathrm{MPa}$ ). This results in a release fraction of $15 \%$. Figure 3 shows how the tritium release fraction falls exponentially with the expansion tank volume. For the peak canister tritium inventory of $5.15 \mathrm{~kg}$, a $15 \%$ release fraction equals $0.77 \mathrm{~kg}$ and produces a site boundary dose of $27.6 \mathrm{mSv}$. Increasing the expansion tank volume to $372 \mathrm{~m}^{3}$, however, reduces the release to $3.2 \%$, and the site boundary dose falls to $5.8 \mathrm{mSv}$. Due to the small volume of the capsules, the Sombrero-like direct-drive design and the bare capsules from the indirect-drive designs would not produce any release even with the 2 m-radius expansion tank. 


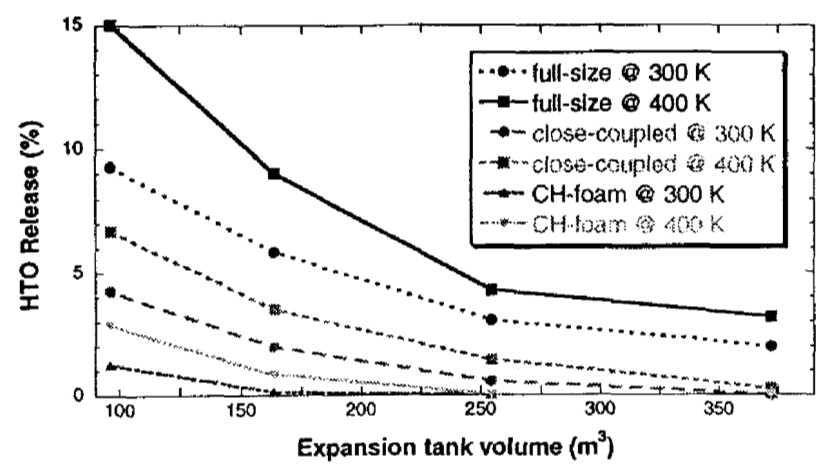

Fig. 3. Tritium release fractions fall rapidly with increasing expansion tank volume.

\section{B. Particulate Results}

The accidental release of high- $\mathrm{Z}$ target materials has been analyzed using the same MELCOR model used for the tritium transport. The target material has been modeled as a fine $(0.1-10 \mu \mathrm{m})$ particulate, and results have been generated for all natural elements from lithium to bismuth. The results should be accurate for any element that would be transported as a particulate during the accident. For elements such as fluorine, for example, chemistry dictates that alternate chemical forms would be taken and the following results are invalid. For most elements, however, these results are indeed of interest.

Figure 4 shows that the high-Z target material release--even in the worst case--is less than $1 \%$. Given that potential tritium releases will drive the facility design towards a larger expansion tank, it seems likely that the high- $Z$ release fraction can be kept to less than $0.3 \%$. Further, a more reasonable PSD of $1-100 \mu \mathrm{m}$ would reduce the release by $\sim 4 \times$. Additional increases in the PSD would further reduce the release percentage.

Using dose conversion factors prepared for previous work, we estimate the early dose resulting from the release of high-Z aerosols. ${ }^{5}$ Calculations have been completed for all elements from lithium to bismuth (except for technetium and dysprosium, which have no stable isotopes). If the release fraction can be limited to $0.3 \%$, then we find that nearly all elements would be acceptable for use. If we arbitrarily allocate $50 \%$ of the total accident dose to the high- $Z$ target material, then a $0.3 \%$ release would be acceptable for all elements except $\mathrm{Co}, \mathrm{Ni}, \mathrm{Br}, \mathrm{Cd}, \mathrm{In}, \mathrm{Te}$, and Eu. Further, all elements come within a factor of six of meeting a $5 \mathrm{mSv}$ dose with a $0.3 \%$ release. This additional factor could easily be obtained by using a realistic PSD.

\section{Combined Safety and Environmental Results}

If we combine the above safety results with the environmental (recycling and waste disposal) results from previous work, we see that environmental considerations dominate over safety. ${ }^{5}$ While nearly all elements would qualify for use based upon the early dose resulting from an accident, only 39 elements qualify based on their waste disposal rating and 27 qualify based upon their contact dose rate (rates chance of recycling). Considering all three criteria, we find that 17 elements qualify for use as the high- $Z$ material. If the contact dose rate limit can be increased by a factor of three (through use of radiation hardened components and/or less time spent near radiation-sensitive components), then the list increases to 25 elements (a $10 \times$ increase in contact dose rate limit would stretch the list to 29 elements). Table II summarizes the results for all elements; codes indicate which criteria, if any, each element fails to meet--the table assumes a $0.3 \%$ release for the accident results.

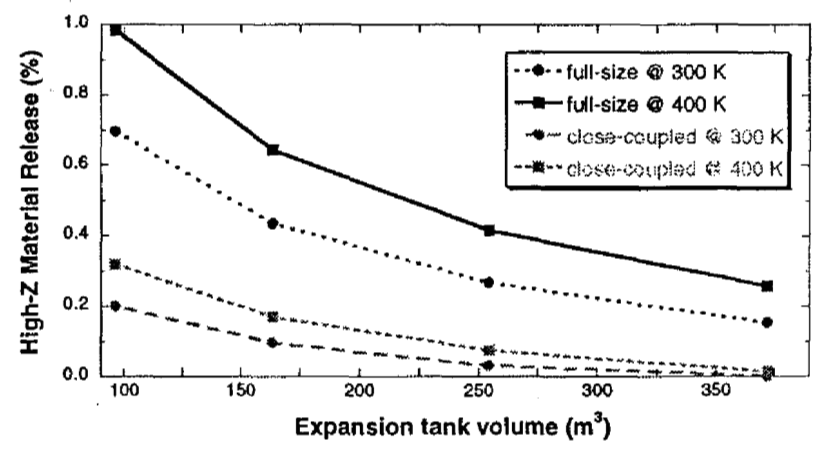

Fig. 4. The release of high- $Z$ target materials was limited to $<1 \%$ in all cases studied.

\section{CONCLUSIONS AND FUTURE WORK}

Our work has concentrated on identifying key features that affect the overall target fabrication tritium inventory, the vulnerable tritium inventory and tritium releases, and the selection of high- $\mathrm{Z}$ target materials.

In the area of total plant tritium inventory, three characteristics make a large difference in the final result. First, the target fill time is crucial in determining the tritium inventory-longer fill times require a higher number of canisters to meet the needs of the power plant. Second, the ability to perform cold assembly (assemble targets that have already been filled) provides a large savings in the tritium inventory for the indirect-drive designs - a factor of 30 for the full-size target and 13 for the close-coupled target. Third, targets with higher burnup result in a target fabrication facility with a lower tritium inventory.

There appear to be two possibilities that may provide a reduction in the target fill time: (1) new materials that can withstand higher temperatures, tolerate higher pressure differentials (are stronger), and/or have higher diffusivities, or (2) new methods for filling targets 
(e.g., injection). In the opinion of the authors, research and development (R\&D) programs are warranted in both areas.

Table II. Codes* for failed safety and environmental criteria for high-Z materials.

\begin{tabular}{cc|cc|cc}
\hline Element & Code & Element & Code & Element & Code \\
\hline $\mathrm{Li}$ & $\mathrm{P}$ & $\mathrm{Be}$ & $\mathrm{P}$ & $\mathrm{B}$ & $\mathrm{P}$ \\
$\mathrm{C}$ & $\mathrm{P}$ & $\mathrm{N}$ & $\mathrm{W}$ & $\mathrm{O}$ & $\mathrm{P}$ \\
$\mathrm{F}$ & $\mathrm{P}$ & $\mathrm{Ne}$ & $\mathrm{P}$ & $\mathrm{Na}$ & $\mathrm{C}$ \\
$\mathrm{Mg}$ & $\mathrm{C}$ & $\mathrm{Al}$ & $\mathrm{CW}$ & $\mathrm{Si}$ & $\mathrm{P}$ \\
$\mathrm{P}$ & $\mathrm{P}$ & $\mathrm{S}$ & $\mathrm{P}$ & $\mathrm{Cl}$ & $\mathrm{W}$ \\
$\mathrm{Ar}$ & $\mathrm{W}$ & $\mathrm{K}$ & $\mathrm{W}$ & $\mathrm{Ca}$ & $\mathrm{W}$ \\
$\mathrm{Sc}$ & $\mathrm{C}$ & $\mathrm{Ti}$ & $\mathrm{C}$ & $\mathrm{V}$ & $\mathrm{C}$ \\
$\mathrm{Cr}$ & $\mathrm{C}$ & $\mathrm{Mn}$ & $\mathrm{C}$ & $\mathrm{Fe}$ & $\mathrm{C}$ \\
$\mathrm{Co}$ & $\mathrm{CA}$ & $\mathrm{Ni}$ & $\mathrm{CWA}$ & $\mathrm{Cu}$ & $\mathrm{C}$ \\
$\mathrm{Zn}$ & $\mathrm{C}$ & $\mathrm{Ga}$ & $\mathrm{P}$ & $\mathrm{Ge}$ & $\mathrm{C}$ \\
$\mathrm{As}$ & $\mathrm{C}$ & $\mathrm{Se}$ & $\mathrm{CW}$ & $\mathrm{Br}$ & $\mathrm{CWA}$ \\
$\mathrm{Kr}$ & $\mathrm{W}$ & $\mathrm{Rb}$ & $\mathrm{C}$ & $\mathrm{Sr}$ & $\mathrm{C}$ \\
$\mathrm{Y}$ & $\mathrm{C}$ & $\mathrm{Zr}$ & $\mathrm{C}$ & $\mathrm{Nb}$ & $\mathrm{CW}$ \\
$\mathrm{Mo}$ & $\mathrm{CW}$ & $\mathrm{Ru}$ & $\mathrm{CW}$ & $\mathrm{Rh}$ & $\mathrm{CW}$ \\
$\mathrm{Pd}$ & $\mathrm{CW}$ & $\mathrm{Ag}$ & $\mathrm{CW}$ & $\mathrm{Cd}$ & $\mathrm{CW}$ \\
$\mathrm{In}$ & $\mathrm{C}$ & $\mathrm{Sn}$ & $\mathrm{P}$ & $\mathrm{Sb}$ & $\mathrm{C}$ \\
$\mathrm{Te}$ & $\mathrm{CWA}$ & $\mathrm{I}$ & $\mathrm{C}$ & $\mathrm{Xe}$ & $\mathrm{C}$ \\
$\mathrm{Cs}$ & $\mathrm{C}$ & $\mathrm{Ba}$ & $\mathrm{C}$ & $\mathrm{La}$ & $\mathrm{P}$ \\
$\mathrm{Ce}$ & $\mathrm{C}$ & $\mathrm{Pr}$ & $\mathrm{P}$ & $\mathrm{Nd}$ & $\mathrm{C}$ \\
$\mathrm{Sm}$ & $\mathrm{CW}$ & $\mathrm{Eu}$ & $\mathrm{CWA}$ & $\mathrm{Gd}$ & $\mathrm{W}$ \\
$\mathrm{Tb}$ & $\mathrm{CW}$ & $\mathrm{Dy}$ & $\mathrm{W}$ & $\mathrm{Ho}$ & $\mathrm{W}$ \\
$\mathrm{Er}$ & $\mathrm{CW}$ & $\mathrm{Tm}$ & $\mathrm{CW}$ & $\mathrm{Yb}$ & $\mathrm{P}$ \\
$\mathrm{Lu}$ & $\mathrm{C}$ & $\mathrm{Hf}$ & $\mathrm{C}$ & $\mathrm{Ta}$ & $\mathrm{C}$ \\
$\mathrm{W}$ & $\mathrm{C}$ & $\mathrm{Re}$ & $\mathrm{CW}$ & $\mathrm{Os}$ & $\mathrm{CW}$ \\
$\mathrm{Ir}$ & $\mathrm{CW}$ & $\mathrm{Pt}$ & $\mathrm{W}$ & $\mathrm{Au}$ & $\mathrm{C}$ \\
$\mathrm{Hg}$ & $\mathrm{P}$ & $\mathrm{Tl}$ & $\mathrm{C}$ & $\mathrm{Pb}$ & $\mathrm{P}$ \\
$\mathrm{Bi}$ & $\mathrm{CW}$ & & & & \\
\hline $\mathrm{Cr}$ & & & & \\
\hline
\end{tabular}

* $\mathbf{C}=$ failed contact dose rate criterion; $\mathrm{W}=$ failed waste management criterion; $\mathrm{A}=$ failed accident dose criterion; $\mathrm{P}=$ passed all criteria.

In the area of accident safety, the total plant tritium inventory does not matter as much as that which is vulnerable. If designs for target fabrication facilities can ensure that canisters/fill rooms can remain isolated from each other (an accident in one does not affect another), then this will go a long way towards meeting the accident safety goals. There will, of course, always be a trade-off between a reasonable number of canisters and the tritium inventory in each. Future work should define the maximum number of canisters. Once this number is reached, reduction of the vulnerable tritium inventory can only be accomplished via cold assembly and/or reductions in the target fill time.

The large reductions in the vulnerable tritium inventory that are offered by cold assembly (13-30x for the two indirect-drive target designs), suggest that an $R \& D$ program should be initiated in this area.

The expansion tank is a valuable tool in limiting releases during an accident. Future work should focus on its optimization-a design that allows failure of a single canister with no release and can accommodate two or more simultaneous failures would be ideal.
To ensure that a wide variety of activated, high- $Z$ materials can be used in a safe manner, future work must investigate the likely chemical makeup of such materials. More materials may be cleared for use if the contact dose rate limit were increased. Both of these will require a better understanding of the extraction, recycling, and manufacturing processes. Finally, limited isotopic separation to remove problematic isotopes should be considered in more detail.

\section{ACKNOWLEDGEMENTS}

The authors would like to thank Lloyd Brown of General Atomics and Wayne Meier of Lawrence Livermore National Laboratory for their useful comments. Work performed under the auspices of the U. S. Department of Energy by University of California Lawrence Livermore National Laboratory under Contract W-7405-Eng-48.

\section{REFERENCES}

[1] "Safety of Magnetic Fusion Facilities: Guidance," DOE-STD-6003-96, U. S. Department of Energy, Washington, D. C. (1996).

[2] D. A. Callahan-Miller and M. Tabak, "A Distributed Radiator, Heavy Ion Target Driven by Gaussian Beams in a Multibeam Illumination Geometry," Nucl. Fusion 39 (Jul. 1999) 883.

[3] D. A. Callahan-Miller and M. Tabak, "Increasing the Coupling Efficiency in a Heavy Ion Inertial Confinement Fusion Target," Nucl. Fusion 39 (Nov. 1999) 1547.

[4] D. A. Callahan-Miller and M. Tabak, "Progress in Target Physics and Design for Heavy Ion Fusion," Phys. Plasmas 7 (May 2000) 2083.

[5] J. F. Latkowski et al., "Selection of IFE Target Materials from a Safety and Environmental Perspective," to appear in Nucl. Inst. Meth. A.

[6] W. R. Meier et al., Osiris and SOMBRERO Inertial Confinement Fusion Power Plant Designs, W. J. Schafer Associates, Inc., DOE/ER/54100-1, WJSA92-01, March 1992.

[7] Bodner, S. E. et al., "High-Gain Direct-Drive Target Design for Laser Fusion," Phys. Plasmas 7 (Jun. 2000) 2298.

[8] L. J. Perkins, personal communication (Aug. 2000).

[9] R..O. Gauntt et al., NUREG/CR-6119, Vol. 1, Rev. 1, SAND97-2398 (1997). 